\title{
Geociências
}

\section{Pegmatito Gentil (Mendes Pimentel, MG) e suas paragêneses mineralógicas de fosfatos raros}

\author{
(Gentil Pegmatite (Mendes Pimentel, MG) and their rare \\ phosphate mineral assemblages)
}

\author{
Mario Luiz de Sá C. Chaves \\ Centro de Pesquisa Prof. Manoel Teixeira da Costa \\ IGC/UFMG, Belo Horizonte. Pesquisador CNPq \\ E-mail:mchaves@igc.ufmg.br \\ Ricardo Scholz \\ Geoaktivan Ltda, Belo Horizonte \\ E-mail:scholz@lycos.com
}

\section{Resumo}

Centenas de corpos pegmatíticos na região nordeste de Minas Gerais produzem minerais gemológicos e de coleção, muitos desses corpos possuindo afinidades com determinada espécie, grupo ou classe mineral. O Pegmatito Gentil em Mendes Pimentel, ora descrito, notabilizase por sua assembléia de minerais fosfáticos, a maior parte dos quais raros ou raríssimos na natureza. A associação mineral identificada inclui microclínio, quartzo, muscovita, almandina-espessartita, berilo e trifilita como fosfato primário, que foi alterado formando uma extensa paragênese de espécies secundárias. Entre essas, destacam-se brazilianita, frondelita, gormanita, huréaulita, lazulita, litiofilita, purpurita, reddingita, woodhouseíta, zanaziíta e, recentemente descrita nesse corpo, a matioliíta.

Palavras-chave: Pegmatitos, minerais fosfáticos, Província Pegmatítica Oriental do Brasil.

\begin{abstract}
Hundreds of pegmatitic bodies occur in the northern region of the State of Minas Gerais, several of these bodies producing gemologic and collection minerals. Such pegmatites are known by the mineral affinity with certain minerals species, groups or classes. The Gentil Pegmatite (Mendes Pimentel county) is characterized by the phosphatic mineral assemblage, and some of these minerals are rare or very rare in nature. Primary species are microcline, quartz, muscovite, almandine-espessartine, beryl, and triphylite as the main phosphate that was altered to an extensive paragenesis of secondary phosphates. In this list are noted brazilianite, frondelite, gormanite, hureaulite, lazulite, lithiophilite, purpurite, reddingite, woodhouseite, zanaziite, and matioliite, a species recently described in the Gentil Pegmatite.
\end{abstract}

Keywords: Pegmatites, phosphate minerals, Eastern Brazil Pegmatitic Province. 


\section{Introdução}

A região nordeste de Minas Gerais, onde se insere a "Província Pegmatítica Oriental do Brasil”, é mundialmente famosa devido à ocorrência de minerais excepcionais pela raridade e/ou por seus aspectos visuais, permitindo com que sejam comercializados no atrativo mercado de minerais para coleção. No contexto dessa província mineral, a região compreendida entre Galiléia, ao sul, passando por Divino das Laranjeiras e se estendendo até Mendes Pimentel, ao norte, destaca-se pela ocorrência de minerais fosfáticos raros ou raríssimos na natureza, diversos deles descritos originalmente na própria região. Nesse caso, incluem-se barbosalita, coutinhoíta, faheyíta, frondelita, lindbergita, moraesita e tavorita em Galiléia; e brazilianita, scorzalita e souzalita em Divino das Laranjeiras (detalhes sobre descrições e depósitos desses minerais encontramse em Pough \& Henderson, 1945, Cassedanne, 1983, Atencio, 2000, Chaves et al., 2006), bem como, de recente descrição, a matioliíta em Mendes Pimentel (Atencio et al., 2006). Esse último mineral foi encontrado no Pegmatito Gentil, cuja geologia e mineralogia detalhada constituem o objetivo central do estudo ora apresentado.

Fanton et al. (1978) e Cassedanne e Cassedanne (1982) realizaram os primeiros estudos de detalhe, enfocando a geologia e mineralogia geral, respectivamente, dos pegmatitos da área. Esses minerais foram também estudados pelos autores e equipe em outras ocasiões (p. ex., Karfunkel et al., 1997, Chaves et al., 2001, 2003, 2005, Scholz, 2002, 2006, Scholz et al., 2003). No Pegmatito Gentil, R. Scholz coletou, em 2003, um mineral de coloração azul-piscina, como agregados de pequenos prismas ( $2-5 \mathrm{~mm}$ ), que logo foi presumido como uma espécie raríssima ou, então, nova para a ciência. Estudos preliminares apontaram que tratar-se-ia, em princípio, de uma burangaíta (Bermanec et al., 2004a, 2004b), embora os resultados químicos não tivessem sido inteiramente satisfatórios. Estudos paralelos e mais completos efetuados por pesquisadores da USP determinaram esse mineral como uma nova espécie, designada matioliíta (Atencio et al., 2006). Como as amostras coletadas pelos presentes autores são de maior tamanho e fazem parte de uma pesquisa integrada envolvendo as paragêneses fosfáticas do depósito, acredita-se que a apresentação dos atuais resultados complementem o citado estudo, bem como ajudem a difundir a imagem do mineral através de fotografia e imagens com MEV de espécimens excepcionais obtidos nos trabalhos de campo.

\section{Localização e contexto geológico regional}

O Pegmatito Gentil (1841’21"S/ 41²7’02"W) localiza-se no município de Mendes Pimentel, o qual dista cerca de $80 \mathrm{~km}$ a leste de Governador Valadares, nordeste de Minas Gerais (Figura 1 - destaque). A partir de Mendes Pimentel, seu acesso pode ser realizado pela rodovia asfaltada MG-417 (que liga a cidade à BR-381), de onde, após 5 km, toma-se uma estrada de terra mal conservada à esquerda em direção à área do Córrego Indaiá. Essa estrada alcança a Lavra do Indaiá, ora explorada para feldspato e, a 2 km para leste, em caminho carroçável, alcança-se a Lavra do Gentil (Figura 1). Ressalte-se, ainda, que, no mapa geológico da região efetuado pelo convênio COMIG/CPRM (Vieira, 2000), essas duas importantes lavras não se encontram cadastradas.

Na região de Mendes Pimentel Divino das Laranjeiras, afloram rochas metassedimentares gnáissicas e/ou xistosas, intrudidas por várias gerações de rochas plutônicas ácidas (Figura 1), todas essas seqüências sendo datadas no Neoproterozóico (Netto et al., 1998). Pegmatitos, associados a tal granitogênese, fazem parte do Campo Pegmatítico Galiléia-Mendes Pimentel, do Distrito Pegmatítico de Conselheiro Pena.

As rochas gnáissicas e xistosas compreendem as Formações Tumiritinga e São Tomé, de natureza metassedimentar, que integram o Grupo Rio Doce.
O relacionamento estratigráfico entre ambas ainda não se encontra exatamente definido. A primeira ocorre a nordeste e sudeste da região, constituída na maior parte por biotita-sillimanita-granada(cordierita) gnaisses, localmente grafitosos. A Formação São Tomé, aflorante sobre a faixa central topograficamente mais arrasada da área, destaca-se por incluir a maioria dos corpos pegmatíticos. A unidade é composta de quartzobiotita-granada xistos, localmente com estaurolita e sillimanita, além de muscovita e schorlita como produtos de metassomatismo. Intercalações de quartzitos impuros e rochas calcissilicáticas são freqüentes. A foliação principal possui direções variáveis com ângulos de mergulhos geralmente elevados.

Intrusivos nesses metassedimentos ocorrem duas fases de magmatismo ácido sintectônico, designadas de Tonalito São Vítor e Tonalito Galiléia, bem como corpos tardi- a pós-tectônicos, estes últimos não representados no mapa da Figura 1 (Féboli, 2000, Vieira, 2000). A Suíte Galiléia constitui a maior parte da região, formando corpos de dimensões batolíticas de rochas leucocráticas a mesocráticas, estrutura gnáissica e textura média a grossa, localmente porfiroblásticas. Essa suíte possui composição metaluminosa a pouco peraluminosa de afinidade cálcio-alcalina e litotipos granitóides do "tipo-I”, representados por tonalitos, tonali-granodioritos, granodioritos e granitos. A Suíte São Vítor, de composição similar, aflora em pequena porção, a oeste de Linópolis, e parece corresponder a uma variedade faciológica do Tonalito Galiléia com estrutura fracamente orientada (Féboli, 2000).

\section{Corpos pegmatíticos da área e o Pegmatito Gentil}

Na região entre Divino das Laranjeiras e Mendes Pimentel, são conhecidos mais de 30 corpos pegmatíticos de porte maior que $2 \mathrm{~m}$, em um quadrilátero de, aproximadamente, $100 \mathrm{~km}^{2}$ (os 20 mais importantes são representados na Figu- 
Mario Luiz de Sá C. Chaves et al.

ra 1). Esses corpos encontram-se encaixados nos biotita-quartzo xistos da Formação São Tomé, geralmente de forma concordante com a xistosidade principal, ou, ainda, condicionados em direções destacadas de fraturamento.

Associados à fase tardia da última granitogênese, os pegmatitos se caracterizam pela presença de uma grande variedade de minerais fosfáticos raros (Chaves et al., 2005), onde se inserem espécies como brazilianita, scorzalita e souzalita, descritas no Pegmatito Córrego Frio (Pough \& Henderson, 1945, Cassedanne, 1983). A maior parte desses pegmatitos possui mineralogia característica de corpos diferenciados, enriquecida em minerais de lítio como ambligonita-montebrasita, trifilita-litiofilita e, mais raramente, lepidolita e espodumênio. Os corpos, geralmente, não apresentam zoneamento textural pronunciado, entretanto possuem porções internas em menor escala com grande variação textural e composicional; nessas porções, aparecem os minerais raros. As dimensões desses corpos variam, em geral, entre 2-30 m de espessura, 10-120 m de comprimento e, para a totalidade dos casos, faltam estudos sobre a profundidade dos corpos.

O Pegmatito Gentil aflora encaixado de forma concordante no biotitaquartzo xisto da Formação São Tomé, no local com direção NNE-SSW mergulhando fortemente para SSE (Figura 2). Esse corpo pegmatítico, diferentemente da maioria dos demais da região, possui zoneamento característico. Nas bordas, a rocha encaixante é metassomatizada (zona marginal), rica em cristais isolados de schorlita. Uma zona mais interna é constituída de pegmatito gráfico, onde já aparecem alguns corpos de substituição (pockets). Estes, porém, são mais abundantes na zona feldspática, rica em grandes cristais de microclínio, com menor volume de quartzo, muscovita, almandina-espessartita, berilo e trifilita como outros minerais primários. O núcleo é de quartzo quase maciço.

Além da trifilita, aparece, em quantidade muito menor, a montebrasita. Nos corpos de substituição, a mineralogia

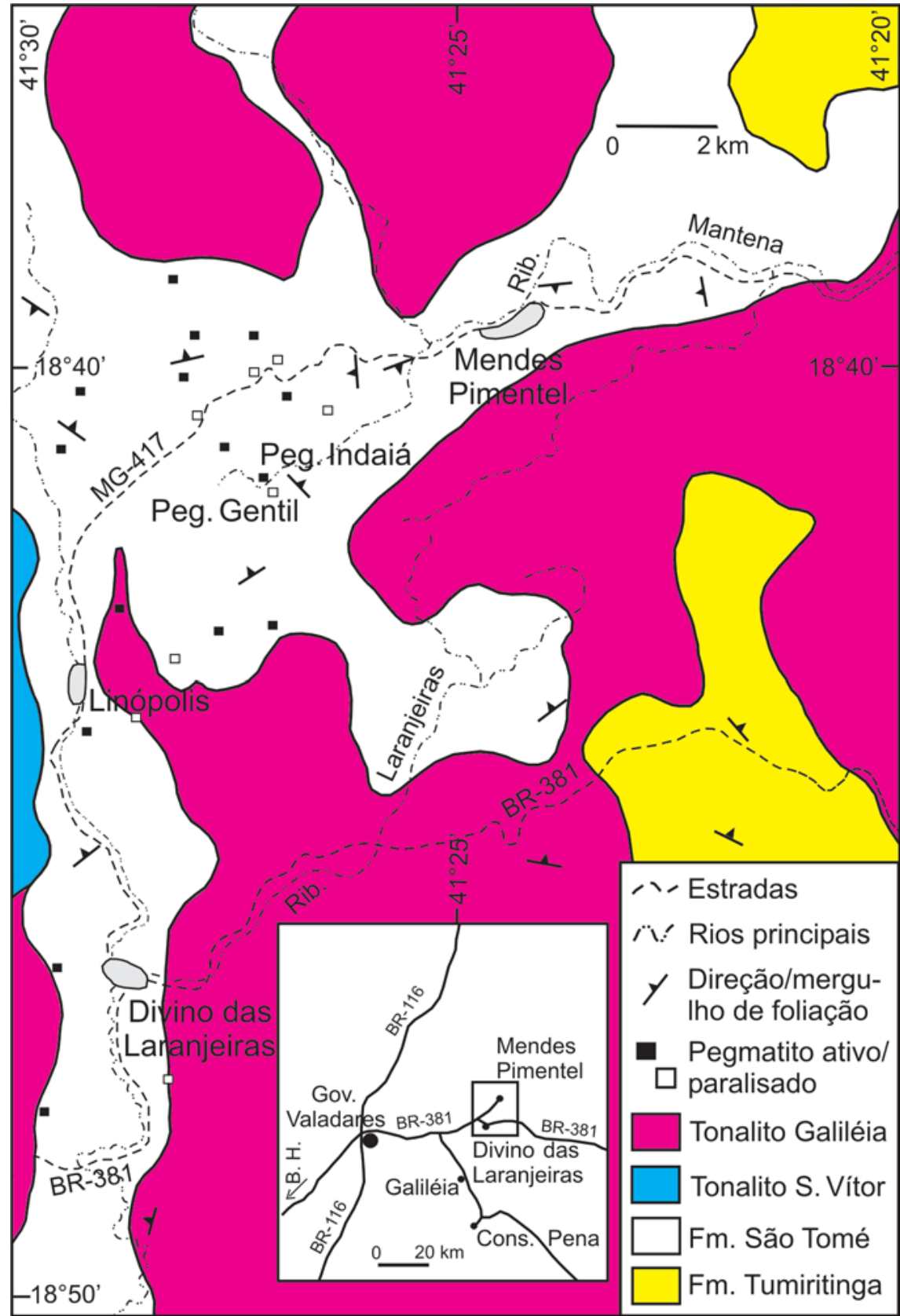

Figura 1 - Geologia da região entre Divino das Laranjeiras e Mendes Pimentel (MG), com a localização do Pegmatito Gentil nesse contexto. Em destaque, abaixo, a localização da mesma região em relação à cidade de Governador Valadares, principal pólo regional de comercialização de minerais gemológicos e de coleção (modificado de Vieira 2000).

secundária é representada por albita, muscovita rica em lítio, elbaíta, além de uma diversificada paragênese de minerais fosfáticos formados a partir da alteração hidrotermal e/ou supergênica da trifilita, que estão descritos no próximo item. A trifilita aparece em cristais euédricos a subédricos, com dimensões va- riáveis entre 0,5 cm e 5 cm incluídos em microclínio e/ou quartzo, bem como constituindo grandes massas agregadas complexas, em conjunto aos mesmos minerais. Em geral, a trifilita encontra-se parcial ou inteiramente substituída, resultando em paragêneses secundárias que incluem espécies fosfáticas raras. 


\section{Paragêneses minerais fosfáticas}

Os processos de diferenciação magmática nos pegmatitos da região permitiram o desenvolvimento de associações minerais variadas, a maioria das quais envolve fases fosfáticas (Tabela 1). A evolução geral da mineralogia dos fosfatos em pegmatitos constitui três etapas distintas (primária, metassomática e hidrotermal), responsáveis pela formação de assembléias e paragêneses específicas, que ocorrem em função da composição química e temperatura do meio (Moore, 1973). Assim, o processo evolutivo vai depender, tanto de fatores internos, como composição química e mineralogia do ambiente primário, quanto de fatores externos, como a possível entrada de água meteórica, de modo que fosfatos primários podem ser submetidos a estágios de alteração com intensidades variáveis. Os processos mais intensos são capazes de substituir, completamente, a mineralogia inicial, mascarando a paragênese primária do corpo, enquanto os de menor intensidade substituem somente parte dela.

Os pegmatitos inseridos no Distrito Pegmatítico de Conselheiro Pena foram, anteriormente, relacionados a seis grupos distintos por Scholz (2002) e Scholz et al. (2003), em função de seus minerais fosfáticos (ou ausência dos mesmos): (I) pegmatitos sem fosfatos primários; (II) pegmatitos pobres em lítio, com triplita; (III) pegmatitos ricos em lítio, com trifilita predominante; (IV) pegmatitos ricos em lítio, com montebrasita predominante; (V) pegmatitos com apatita e (VI) pegmatitos com monazita. Tendo por base tal classificação, descrevemse paragêneses presentes em pegmatitos do "tipo III", onde se insere o Pegmatito Gentil, bem como diversos outros corpos nos arredores de Galiléia, ao sul, a exemplo das lavras Boca Rica, Cigana, Sapucaia e Boa Vista-1 (Chaves et al., 2005). Em todos esses corpos, a trifilita ocorre fazendo parte da mineralogia primária junto com microclínio, quartzo e berilo, formando associações com numerosos minerais de alteração, alguns destes de origem supergênica.

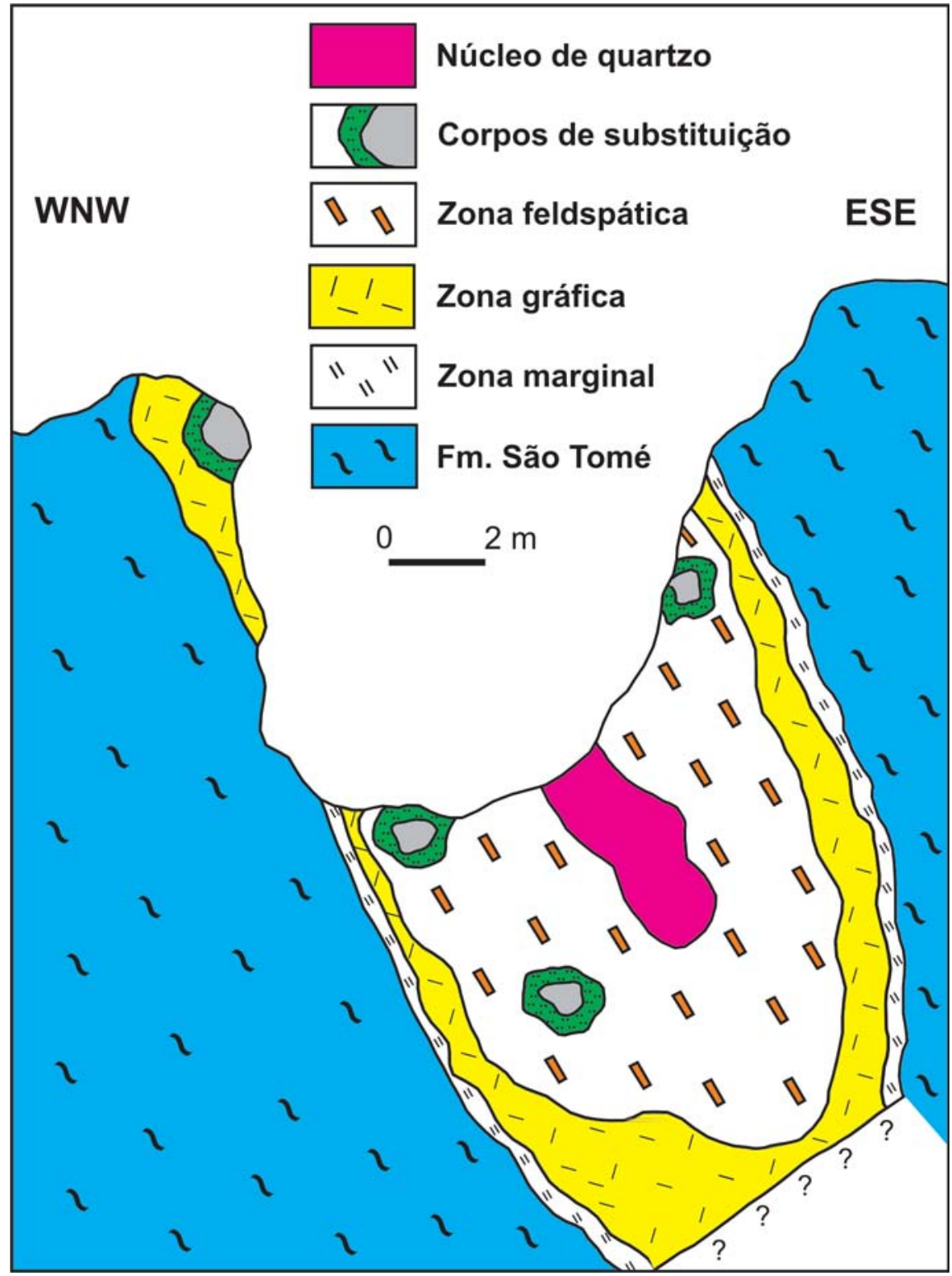

Figura 2 - Seção geológica esquemática levantada no Pegmatito Gentil, ressaltando seu zoneamento típico e anômalo para os corpos da região.

No Pegmatito Gentil, as paragêneses mais comuns verificadas foram (fórmulas químicas segundo o IMA (Mandarino \& Back, 2004):

- Trifilita $\left[\mathrm{LiFe}^{2+} \mathrm{PO}_{4}\right]+$ fosfossiderita $\left[\mathrm{Fe}^{3+} \mathrm{PO}_{4} \cdot 3 \mathrm{H}_{2} \mathrm{O}\right]+$ purpurita $\left[\mathrm{Mn}^{3+} \mathrm{PO}_{4}\right]$. Essa associação corresponde a agregados de cristais de trifilita de cor verde-escura, inseridos no microclínio e com as bordas parcialmente alteradas para fosfosiderita e/ou purpurita (Figura 3).

- (Trifilita $)+$ reddingita $\left[\mathrm{Mn}^{2+} \mathrm{Mn}^{2+}{ }_{2}\left(\mathrm{PO}_{4}\right)_{2}\left(\mathrm{H}_{2} \mathrm{O}\right)\right]+$ huréaulita $\left[\mathrm{Mn}_{5}^{2+}\left(\mathrm{PO}_{4}\right)_{2} \mathrm{PO}_{3}(\mathrm{OH})_{2} \cdot 4 \mathrm{H}_{2} \mathrm{O}\right]+$ fosfossiderita. Tal paragênese constitui produto de alteração da trifilita e está presente em cavidades de substituição/alteração tardias (Figura 4A), ou em substituição total a cristais de trifilita. No primeiro caso, cristais de litiofilita apresentam reddingita e huréaulita na superfície ou em cavidades. 
Mario Luiz de Sá C. Chaves et al.

Tabela 1 - Relação das espécies minerais fosfáticas encontradas em pegmatitos representativos da região de Divino das Laranjeiras - Mendes Pimentel (lavras de 1 até 6), destacando em negrito o Pegmatito Gentil, em comparação aos pegmatitos das proximidades de Galiléia, ao sul (lavras de 7 até 13) (parcial e modificado de Scholz, 2002 e Chaves et al., 2005).

\begin{tabular}{|c|c|c|c|c|c|c|c|c|c|c|c|c|c|}
\hline$\underset{\square}{\stackrel{\infty}{\alpha}}$ & 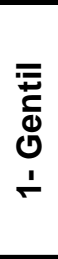 & 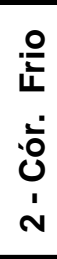 & 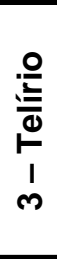 & 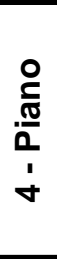 & 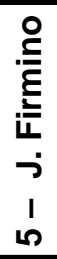 & 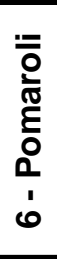 & 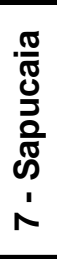 & 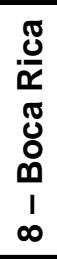 & 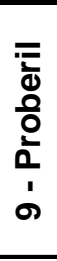 & 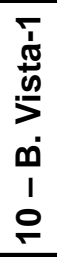 & 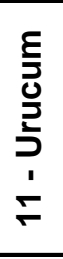 & 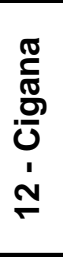 & 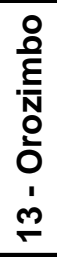 \\
\hline \multicolumn{14}{|l|}{ MINERAIS } \\
\hline Ambligonita-montebrasita & $\mathbf{x}$ & $x$ & $x$ & & $x$ & $x$ & & & $x$ & $x$ & & & \\
\hline Arrojadita & & & & & & & $x$ & & & $x$ & & & \\
\hline Autunita & & & & & $x$ & & $x$ & $x$ & & & $x$ & & \\
\hline Barbosalita & & & & & & & $x$ & $x$ & & & & & \\
\hline Berilonita & & & $x$ & & & & & & & $x$ & & $x$ & \\
\hline Brazilianita & $\mathbf{x}$ & $x$ & $x$ & $x$ & $x$ & $x$ & & & & & & & \\
\hline Cacoxenita & & & & & & & $x$ & $x$ & & & & $x$ & \\
\hline Childrenita-eosforita & $\mathbf{x}$ & $x$ & $x$ & $x$ & $x$ & $x$ & $x$ & $x$ & & $x$ & & & \\
\hline Faheyíta & & & & & & & & $x$ & & & & & \\
\hline Ferrisiklerita & & & $x$ & & & & $x$ & $x$ & $x$ & & & & \\
\hline Fluorapatita & $\mathbf{x}$ & $x$ & $x$ & $x$ & $x$ & $x$ & $x$ & $x$ & & $x$ & $x$ & & $x ?$ \\
\hline Fosfosiderita & $\mathbf{x}$ & & $x$ & & $x$ & $x$ & $x$ & $x$ & & $x$ & & $x$ & \\
\hline Fosfouranilita & & & $x$ & & & & $x$ & & & $x$ & $x$ & & \\
\hline Frondelita & $\mathbf{x}$ & $x$ & $x$ & & $x$ & $x$ & $x$ & $x$ & & $x$ & & & \\
\hline Gormanita & $\mathbf{x}$ & $x$ & $x$ & & $x$ & & & $x ?$ & & & & & \\
\hline Heterosita-purpurita & $\mathbf{x}$ & $x$ & $x$ & & $x$ & $x$ & $x$ & $x$ & $x$ & $x$ & & & \\
\hline Hidroxiherderita & & & $x$ & $x$ & $x$ & & $x$ & & & $x$ & & & \\
\hline Huréaulita & $x$ & & & & & & $x$ & $x$ & & & $x ?$ & & \\
\hline Litiofilita & $\mathbf{x}$ & & & & & & & & & & & & \\
\hline Matioliíta & $\mathbf{x}$ & & & & & & & & & & & & \\
\hline Moraesita & & & $x$ & $x$ & $x$ & & $x$ & & & & & & \\
\hline Reddingita & $\mathbf{x}$ & & & & & & & & & & & $x$ & \\
\hline Roscherita-zanaziíta & $\mathbf{x}$ & $x$ & & & $x$ & $x$ & $x$ & $x$ & & $x$ & & & \\
\hline Scorzalita-lazulita & $\mathbf{x}$ & $x$ & & & & & $x$ & & & & & & \\
\hline Sicklerita & $\mathbf{x}$ & & & & & & & & & & & $x$ & \\
\hline Souzalita & & $x$ & & & & & & $x$ & & & & & \\
\hline Tavorita & & & & & & & $x$ & & & & & & \\
\hline Trifilita & $\mathbf{x}$ & & & & & & $x$ & & $x$ & $x$ & & & \\
\hline Triplita & & & & & & & & & & $x$ & & & \\
\hline Vivianita & $x$ & & $x$ & & & & $x$ & & & $x$ & $x$ & $x$ & \\
\hline Woodhouseíta & $\mathbf{x}$ & & & & & & & & & & & & \\
\hline
\end{tabular}


- (Triflilita) + frondelita $\left[\mathrm{Mn}^{2+} \mathrm{Fe}^{3+}{ }_{4}\left(\mathrm{PO}_{4}\right)_{3}(\mathrm{OH})_{5}\right]+$ litiofilita $\left[\mathrm{LiMn}^{2+} \mathrm{PO}_{4}\right]+$ lazulita $\left[\mathrm{MgAl}_{2}\left(\mathrm{PO}_{4}\right)_{2}(\mathrm{OH})_{2}\right]+$ huréaulita. A frondelita aparece recobrindo corpos de substituição tardios e, sobre esse mineral, ocorrem litiofilita, huréaulita e/ou lazulita. Estão também relacionados à substituição total da trifilita.

- (Trifilita) + frondelita + ferrissicklerita $\left[\mathrm{Li}\left(\mathrm{Fe}^{3+}, \mathrm{Mn}^{2+}\right) \mathrm{PO}_{4}\right]+$ purpurita. Essa paragênese ocorre como produto de alteração da trifilita, formando blocos maciços. A purpurita é formada a partir da seguinte seqüência de alterações: trifilita-litiofilita $\rightarrow$ sicklerita-ferrissicklerita $\rightarrow$ purpurita-heterosita.

- (Trifilita) + fluorapatita $\left[\mathrm{Ca}_{5}\left(\mathrm{PO}_{4}\right)_{3} \mathrm{~F}\right]+$ brazilianita $\left[\mathrm{NaAl}_{3}\left(\mathrm{PO}_{4}\right)_{2}(\mathrm{OH})_{4}\right]+$ woodhouseíta $\left\{\mathrm{CaAl}_{3}\left[(\mathrm{P}, \mathrm{S}) \mathrm{O}_{4}\right]_{2}\left(\mathrm{OH}, \mathrm{H}_{2} \mathrm{O}\right)_{6}\right\}+$ matioliíta $\left[(\mathrm{Na}, \mathrm{Mg}) \mathrm{Al}_{5}\left(\mathrm{PO}_{4}\right)_{4}(\mathrm{OH})_{6} \cdot 2 \mathrm{H}_{2} \mathrm{O}\right]$. Nes-

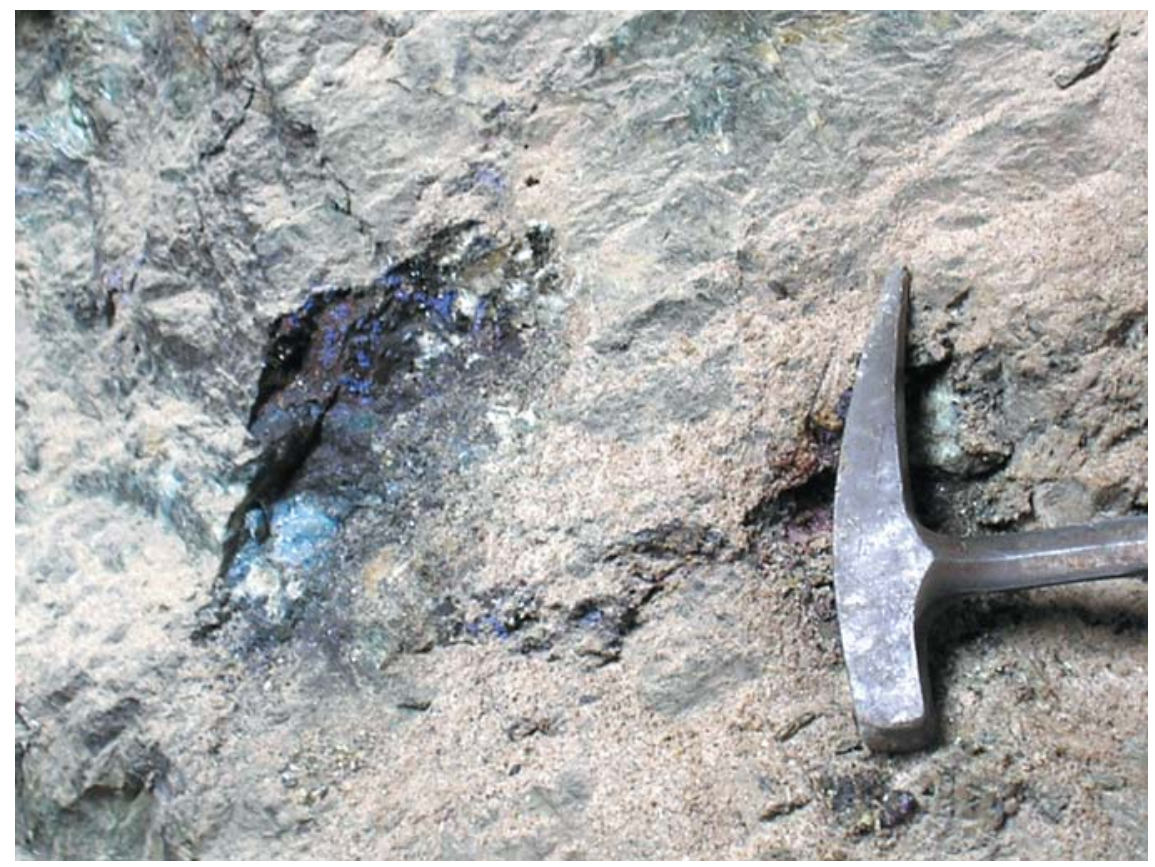

Figura 3 - Pequeno corpo de substituição no pegmatito, mostrando a trifilita verdeescura sendo alterada nas bordas para fosfossiderita azul-clara (borda inferior) e purpurita roxa (borda superior). sa paragênese, a trifilita encontra-se inteiramente substituída, verificandose uma interessante e singular associação de fluorapatita (secundária), brazilianita mal cristalizada, woodhouseíta em pseudocubos (única ocorrência brasileira do mineral conhecida) e da recentemente descrita matioliíta, com cristais azuis milimétricos em prismas longos (Figura 4B).

\section{Química mineral dos fosfatos em geral e da matioliíta do corpo}

Análises químicas com microssonda eletrônica foram efetuadas em amostras representativas de matioliíta (Figura 5A), brazilianita, frondelita, lazulita e trifilita (Tabela 2), após suas identificações com difração de raios X. As análises com microssonda foram obtidas no Laboratório de Microanálises, Defis-ICEX/UFMG. Na coluna 1 dessa tabela, apresentam-se os dados de amostra coletada em 2003, então considerada como burangaíta $\left[(\mathrm{Na}, \mathrm{Ca})\left(\mathrm{Fe}^{2+}, \mathrm{Mg}\right) \mathrm{Al}_{5}\left(\mathrm{PO}_{4}\right)_{4}(\mathrm{OH}, \mathrm{O})_{6} \cdot 2 \mathrm{H}_{2} \mathrm{O}\right]$ (Bermanec et al., 2004a, 2004b), posteriormente reconhecida por Atencio et al. (2006) como nova espécie (matioliíta) compondo uma série isomórfica com a primeira. Imagens de microscopia eletrônica de varredura detalham os prismas

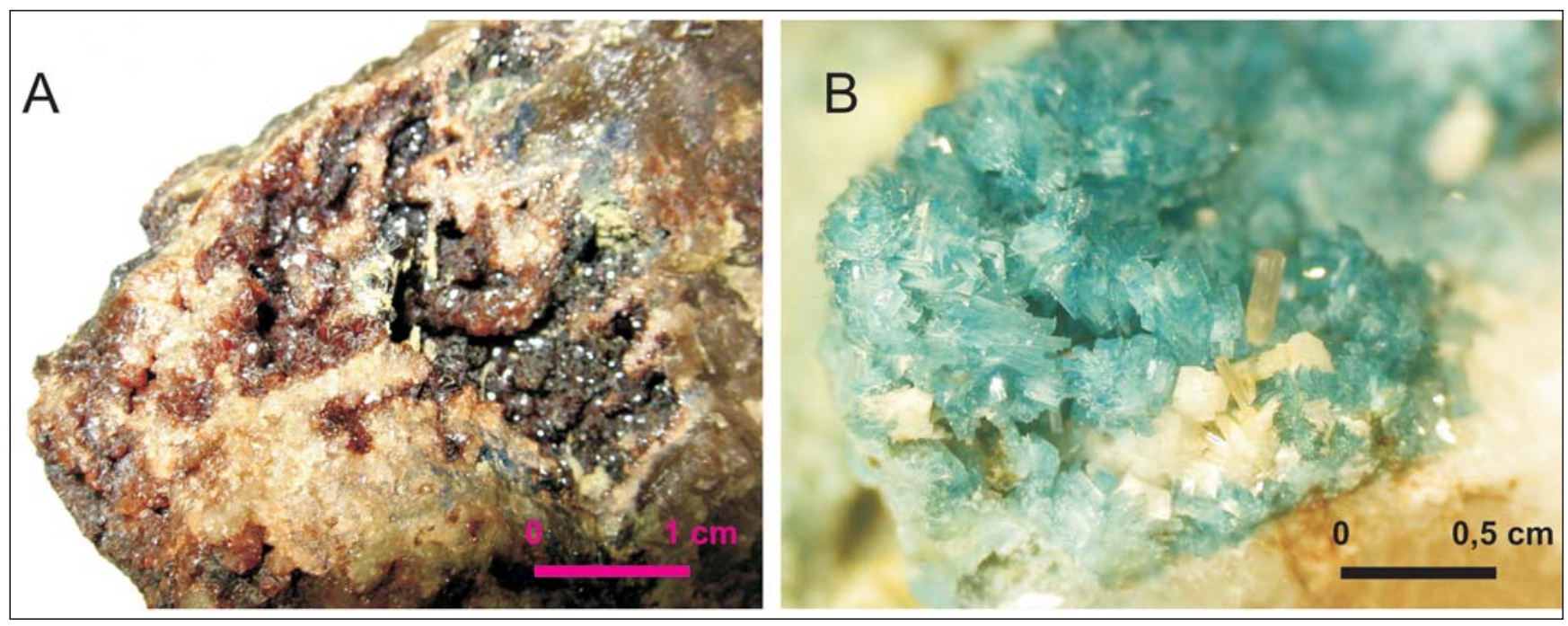

Figura 4 - (A) Cavidade na trifilita, onde esta é substituída por reddingita (preta) e huréaulita (marrom), com raros cristais de fosfossiderita (azul). (B) Prismas de matioliíta (azul) com intercrescimentos de woodhouseíta (pseudocubos brancos) e apatita (prismas amarelos)(Fotografia L. Menezes Filho). 
Mario Luiz de Sá C. Chaves et al.

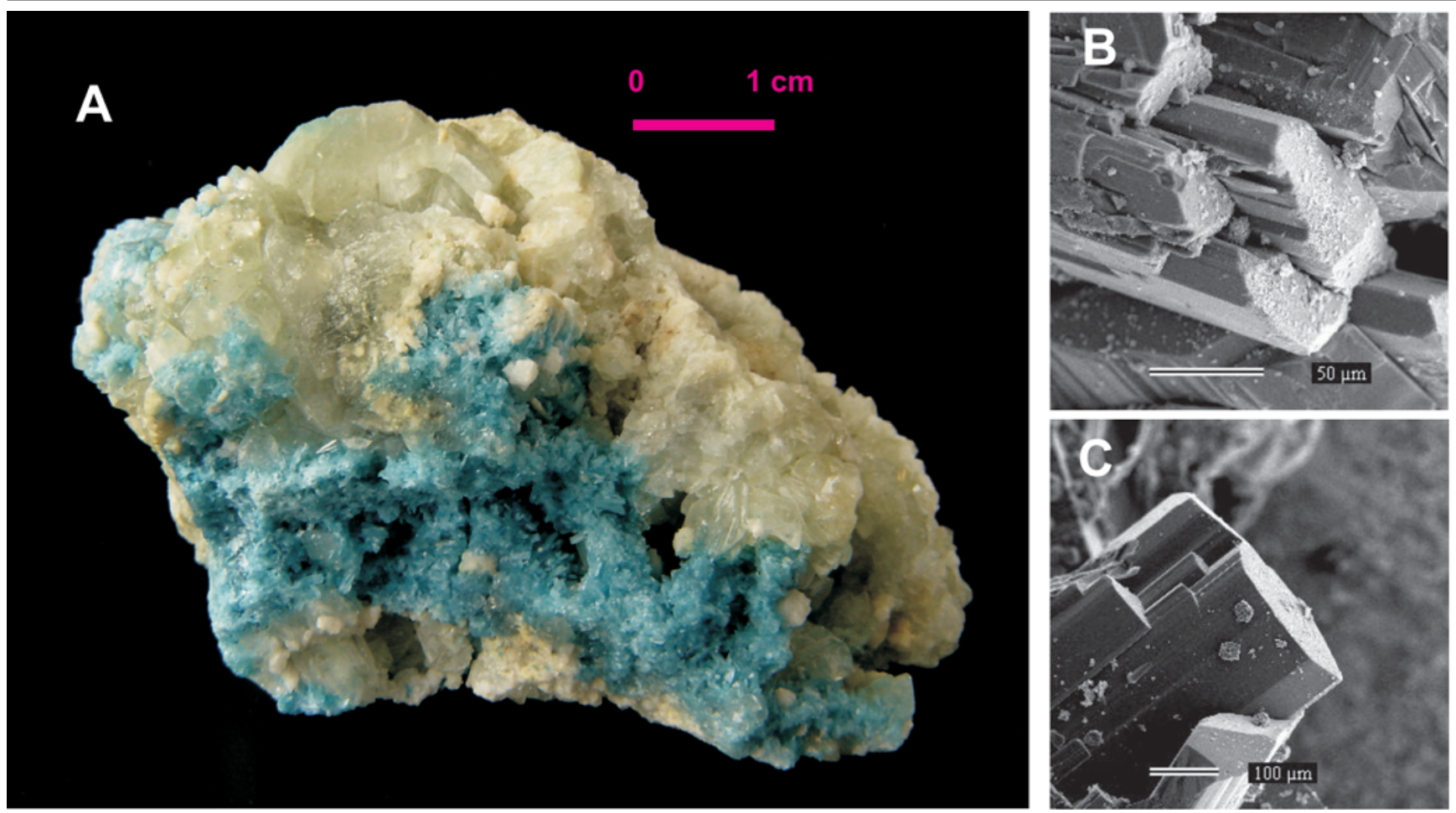

Figura 5 - (A) Agregado de cristais prismáticos de matioliíta de excelente qualidade (prismas individuais com até 2-3 mm de comprimento), incrustado em massas disformes de brazilianita (verde) e rara albita (branca). (B) e (C) Fotomicrografias eletrônicas obtidas de cristalitos da mesma amostra, ressaltando os prismas monoclínicos da matiolí́ta e suas terminações perfeitas em (001). (A - Fotografia de A. Liccardo; B e C - Fotomicrografias obtidas em MEV no Lab. de Microanálises, Defis-ICEX/UFMG)

Tabela 2 - Análises químicas com microssonda eletrônica (\% em peso) de amostras de fases fosfáticas secundárias (1 até 6 ) e primária (7 até 9) representativas do Pegmatito Gentil. (1) Matiolíta; (2) e (3) Matiolíta e uma fase rica em ferro correspondendo a uma composição intermediária entre burangaíta e matioliíta, respectivamente; (4) Burangaíta; (5) Brazilianita; (6) Frondelita; (7) Lazulita; (8), (9) e (10) Trifilita, amostras obtidas de três diferentes pockets. Colunas (2) e (3), dados comparativos de Atencio et al (2006), e coluna (4) de Knorring et al. (1977). Nas demais colunas, médias agora obtidas de 10 análises em cada amostra. (*) Todo ferro calculado como $\mathrm{Fe}^{2+}$; (Nd) Não determinado; - Abaixo do limite de detecção.

\begin{tabular}{c|c|c|c|c|c|c|c|c|c|c}
\hline Óxidos & $\mathbf{( 1 )}$ & $\mathbf{( 2 )}$ & $\mathbf{( 3 )}$ & $\mathbf{( 4 )}$ & $\mathbf{( 5 )}$ & $\mathbf{( 6 )}$ & $\mathbf{( 7 )}$ & $\mathbf{( 8 )}$ & $\mathbf{( 9 )}$ & $\mathbf{( 1 0 )}$ \\
\hline $\mathrm{Li}_{\mathbf{2}} \mathbf{O}$ & $\mathrm{Nd}$ & $\mathrm{Nd}$ & $\mathrm{Nd}$ & $\mathrm{Nd}$ & $\mathrm{Nd}$ & $\mathrm{Nd}$ & $\mathrm{Nd}$ & $\mathrm{Nd}$ & $\mathrm{Nd}$ & $\mathrm{Nd}$ \\
\hline $\mathrm{Na}_{\mathbf{2}} \mathbf{O}$ & 1,28 & 4,07 & 3,88 & 2,93 & 3,37 & 0,02 & - & 0,01 & 0,01 & - \\
\hline $\mathbf{C a O}$ & 0,05 & 0,06 & 0,08 & 1,88 & 0,15 & 0,33 & 0,01 & 0,01 & 0,03 & 0,02 \\
\hline $\mathbf{M g O}$ & 4,68 & 4,92 & 2,76 & 2,00 & 0,09 & 0,05 & 11,44 & 1,51 & 1,47 & 1,45 \\
\hline $\mathbf{M n O}$ & 0,06 & 0,14 & 0,08 & 0,4 & 0,02 & 10,71 & 0,01 & 9,53 & 9,26 & 9,12 \\
\hline $\mathbf{F e O}$ & $\star 2,20$ & 1,10 & 4,99 & 6,26 & $* 0,14$ & $* 42,07$ & $\star 1,79$ & $\star 32,90$ & $\star 31,64$ & $\star 30,80$ \\
\hline $\mathbf{F e}_{\mathbf{2}} \mathbf{O}_{\mathbf{3}}$ & $\mathrm{Nd}$ & 1,45 & 0,55 & 1,14 & $\mathrm{Nd}$ & $\mathrm{Nd}$ & $\mathrm{Nd}$ & $\mathrm{Nd}$ & $\mathrm{Nd}$ & $\mathrm{Nd}$ \\
\hline $\mathbf{A l}_{\mathbf{2}} \mathbf{O}_{\mathbf{3}}$ & 39,82 & 36,36 & 34,90 & 34,35 & 45,81 & - & 30,66 & 0,01 & - & - \\
\hline $\mathbf{P}_{\mathbf{2}} \mathbf{O}_{\mathbf{5}}$ & 42,70 & 39,79 & 38,98 & 37,65 & 41,67 & 32,27 & 48,17 & 47,20 & 46,91 & 46,53 \\
\hline $\mathbf{H}_{\mathbf{2}} \mathbf{O}+$ & $\mathrm{Nd}$ & 12,19 & 12,52 & 11,60 & 10,36 & $\mathrm{Nd}$ & $\mathrm{Nd}$ & $\mathrm{Nd}$ & $\mathrm{Nd}$ & $\mathrm{Nd}$ \\
\hline $\mathrm{Total}_{\mathbf{1}}$ & 90,79 & 98,08 & 98,74 & 100,27 & 101,61 & 85,45 & 92,11 & 91,17 & 89,32 & 87,92 \\
\hline
\end{tabular}


alongados extraídos da mesma amostra (Figura 5B-C). Nas colunas 2 e 3, são fornecidas, comparativamente, as análises pertinentes desses últimos autores em relação ao novo mineral e a uma outra fase de composição intermediária na referida série e, na coluna 4 , valores da burangaíta da localidade-tipo, o Pegmatito Buranga, em Ruanda (Knorring et al., 1977). Os dados apresentados indicam que a matioliíta ora analisada é empobrecida em $\mathrm{Na}_{2} \mathrm{O}$ e relativamente mais rica em $\mathrm{P}_{2} \mathrm{O}_{5}$ e $\mathrm{Al}_{2} \mathrm{O}_{3}$.

Na coluna 5 (Tabela 2), constam os dados da brazilianita que se associa à matioliíta, apresentados na Figura 5A. A brazilianita, embora descrita desde longa data (Pough \& Henderson, 1945), é, ainda, um mineral pouco estudado. Análises desses autores obtidas a partir de amostras da localidade-tipo, Pegmatito Córrego Frio (situado no mesmo município - mineralogia geral mostrada na Tabela 1 ), possuem valores de $\mathrm{Na}_{2} \mathrm{O}$ da ordem de 8,4\%, entretanto o espécime analisado também é empobrecido nesse óxido, com $\pm 3,4 \%$. Tais dados, juntamente com os apresentados para frondelita e lazulita do mesmo corpo (Tabela 2, colunas 6-7), demonstram a complexidade química dos fosfatos secundários encontrados, que, muitas vezes, se comportam como misturas de distintas fases e/ou ainda exibem diversos graus de hidratação. Assim, a frondelita da coluna 6 dessa tabela, com $\pm 42,1 \%$ de $\mathrm{FeO}$ contra $\pm 49,3 \%$ requeridos para valores ideais, pode indicar maior hidratação do material analisado. Os outros valores são muito semelhantes aos valores ideais. Os baixos fechamentos nas análises desses dois minerais devem-se à presença da hidroxila, não quantificável na microssonda.

Quanto às fases primárias do Pegmatito Gentil, ocorre trifilita e, de modo raro, ocorre a montebrasita. A lazulita também é um fosfato primário característico (Moore, 1973), entretanto esse autor lista, ainda, tal espécie como uma possível fase secundária, o que, provavelmente, representa a amostra analisada (Tabela 2 , coluna 7). A mesma possui grande semelhança química com lazulitas da região de Diamantina, embora estas últimas ocorram em veios de quartzo (Chaves et al., 2003). A trifilita, que foi analisada a partir de amostras de três diferentes corpos de substituição (Tabela 2, colunas 8, 9 e 10), também apresentou anomalia quanto ao $\mathrm{FeO}$, com 30,8-32,9\% contra 45,5\% requeridos para valores ideais; entretanto o $\mathrm{MnO}$ (não presente na fórmula química teórica) alcançou até $\pm 9,5 \%$ nas análises, indicando um importante processo substitucional do $\mathrm{Fe}^{2+}$, pelo $\mathrm{Mn}^{2+}$, e resultando numa provável fase intermediária entre esse mineral e a litiofilita.

\section{Considerações finais}

O estudo regional da geologia e da mineralogia fosfática primária e secundária encontrada nos pegmatitos do Distrito de Conselheiro Pena tem permitido a identificação de diversos tipos de pegmatitos com base em suas constituições minerais, além de possibilitar a caracterização de modo integrado das assembléias e paragêneses minerais com espécies raras envolvidas. A descrição de onze novos minerais em pegmatitos dessa região (barbosalita, brazilianita, coutinhoíta, faheyíta, frondelita, lindbergita, matioliíta, moraesita, scorzalita, souzalita e tavorita), bem como a diversidade demonstrada, abre um campo largamente potencial para a descoberta de outros novos minerais na mesma. O Pegmatito Gentil, embora com atividades de lavra paralisadas desde 2004, possui, ainda, pilhas de rejeito interessantes de serem exploradas, tendo em vista o encontro de novas associações minerais.

O estudo desenvolvido nesse pegmatito integra-se com os de outros corpos da região de Mendes Pimentel, o que deve constituir objeto de futuro trabalho. A caracterização química de distintas paragêneses minerais com espécies fosfáticas envolveu análises químicas com microssonda eletrônica na principal fase primária (trifilita) e sobre algumas fases secundárias presentes (brazilianita, frondelita, lazulita e matioliíta), res- saltando-se importantes processos de substituição. Deve-se, ainda, frisar que a matioliíta, recentemente descrita nesse corpo, assim como as fases estudadas quimicamente e que apresentaram diferenças consideráveis em relação às composições químicas ideais, constitui um campo de pesquisas que pode contribuir para um melhor entendimento da evolução da mineralogia fosfática em pegmatitos.

\section{Agradecimentos}

O primeiro autor agradece à FAPEMIG - Fundação de Amparo à Pesquisa do Estado de Minas Gerais, pelo apoio financeiro concedido através do Projeto de Pesquisa EDT-2244/05.

\section{Referências bibliográficas}

ATENCIO, D. Type mineralogy of Brazil. São Paulo: Museu de Geociências IG-USP, 2000. 114p.

ATENCIO, D. et alii. Matioliite, the Mganalog of burangaite, from Gentil mine, Mendes Pimentel, Minas Gerais, Brazil, and other occurrences. Am. Mineral., v.91, p.1932-1936, 2006.

BERMANEC, V. et alii. Associação de burangaíta e brazilianita em pegmatito de Divino das Laranjeiras, Minas Gerais. In: CONGR. BRAS. GEOL., 42, 2004, Araxá. CD-ROM... Araxá: SBG, 2004a, Resumo 25-1009.

BERMANEC, V. et alii. Burangaite and brazilianite association from Divino das Laranjeiras, Minas Gerais, Brazil. In: INTERNAT. GEOL. CONG., 32nd, 2004, Florence. Scientific Sessions Abstracts... Florence, 2004b, Part 1, p.215.

CASSEDANNE, J.P. Famous mineral localities: the Córrego Frio mine and vicinity, Minas Gerais, Brazil. Min. Record, v.14, p.227-237, 1983.

CASSEDANNE, J.P., CASSEDANNE, J.O. Phosphates et arséniures du basin supérieur du Ribeirão Laranjeiras (Minas Gerais). An. Acad. Bras. Cienc., v.54, n.1, p.165184, 1982.

148 REM: R. Esc. Minas, Ouro Preto, 61(2): 141-149, abr. jun. 2008 
Mario Luiz de Sá C. Chaves et al.

CHAVES, M.L.S.C. et alii. Aspectos químicos e mineralógicos dos fosfatos da série eosforita-childrenita em pegmatitos de Minas Gerais e Rio Grande do Norte. In: CONGR. BRAS. GEOL., 11, 2001, BeloHorizonte. Anais... Belo Horizonte: SBG, 2001, CD-ROM.

CHAVES, M.L.S.C. et alii. Rare gem mineral deposits from Brazil, Part 2: Lazulite and scorzalite. Australian Gemmologist, v.21, n.10, p.390-399, 2003.

CHAVES, M.L.S.C. et alii. Assembléias e paragêneses minerais singulares nos pegmatitos da região de Galiléia (Minas Gerais). Geociências, v.24, n.2, p.143-161, 2005.

FANTON, J.J. et alii. Pegmatitos da região de Galiléia - Mendes Pimentel, MG. In: In: CONGR. BRAS. GEOL., 30, 1978, Recife. Anais... Recife: SBG, 1978, v.4, p.1770-1781.

FÉBOLI, W.L. Projeto Leste - Província Pegmatítica Oriental, Folha Governador Valadares. Belo Horizonte: COMIG/CPRM, 2000.54p.
KARFUNKEL, J. et alii. Ernstite and eosphorite from Minas Gerais, Brasil. Min. Record, v.28, p.489-493, 1997.

KNORRING, O. et alii. Burangaite, a new phosphate mineral from Rwanda. Bull. Geol. Soc. Finland, v.49, p.33-36, 1977.

MANDARINO, J.M., BACK, M.E. Fleischer's glossary of mineral species. Tucson: Mineralogical Record, 2004. 309p.

MOORE, B.P. Pegmatite phosphates: descriptive mineralogy and crystal chemistry. Min. Record, v.4, p.103-130, 1973.

NETTO, C. et alii. Projeto Leste - Província Pegmatítica Oriental, Relatório Final. Belo Horizonte: COMIG/CPRM, 1998. 223p.

POUGH, F.H., HENDERSON, E.P. Brazilianite, a new phosphate mineral. Am. Mineral., v.30, p.572-582, 1945.

SCHOLZ, R. Mineralogia fosfática dos pegmatitos do Distrito de Conselheiro Pena, Minas Gerais. Belo Horizonte: IGC-UFMG, 2002. 185p. (Dissertação de Mestrado).

SCHOLZ, R. Estudo dos fosfatos do Distrito Pegmatítico de Conselheiro Pena, Minas Gerais. Belo Horizonte: IGC-UFMG, 2006. 120p. (Tese de Doutorado).

SCHOLZ, R. et alii. O Pegmatito Gentil: mineralogia fosfática primária e seus produtos de alteração. In: CONGR. BRAS. GEOL., 41, 2002, João Pessoa. Anais... João Pessoa: SBG, 2002. p.607.

SCHOLZ, R. et alii. Pegmatitos do Distrito de Conselheiro Pena: classificação quanto à mineralogia fosfática primária. In: SIMP. GEOL. MINAS GERAIS, 12. Ouro Preto. Anais... Ouro Preto: SBG-MG, 2003. p.67.

VIEIRA, V.S. Projeto Leste - Província Pegmatítica Oriental, Folha Itabirinha de Mantena. Belo Horizonte: COMIG/CPRM, 2000. 57p.

Artigo recebido em 27/03/2007 e aprovado em 25/02/2008.

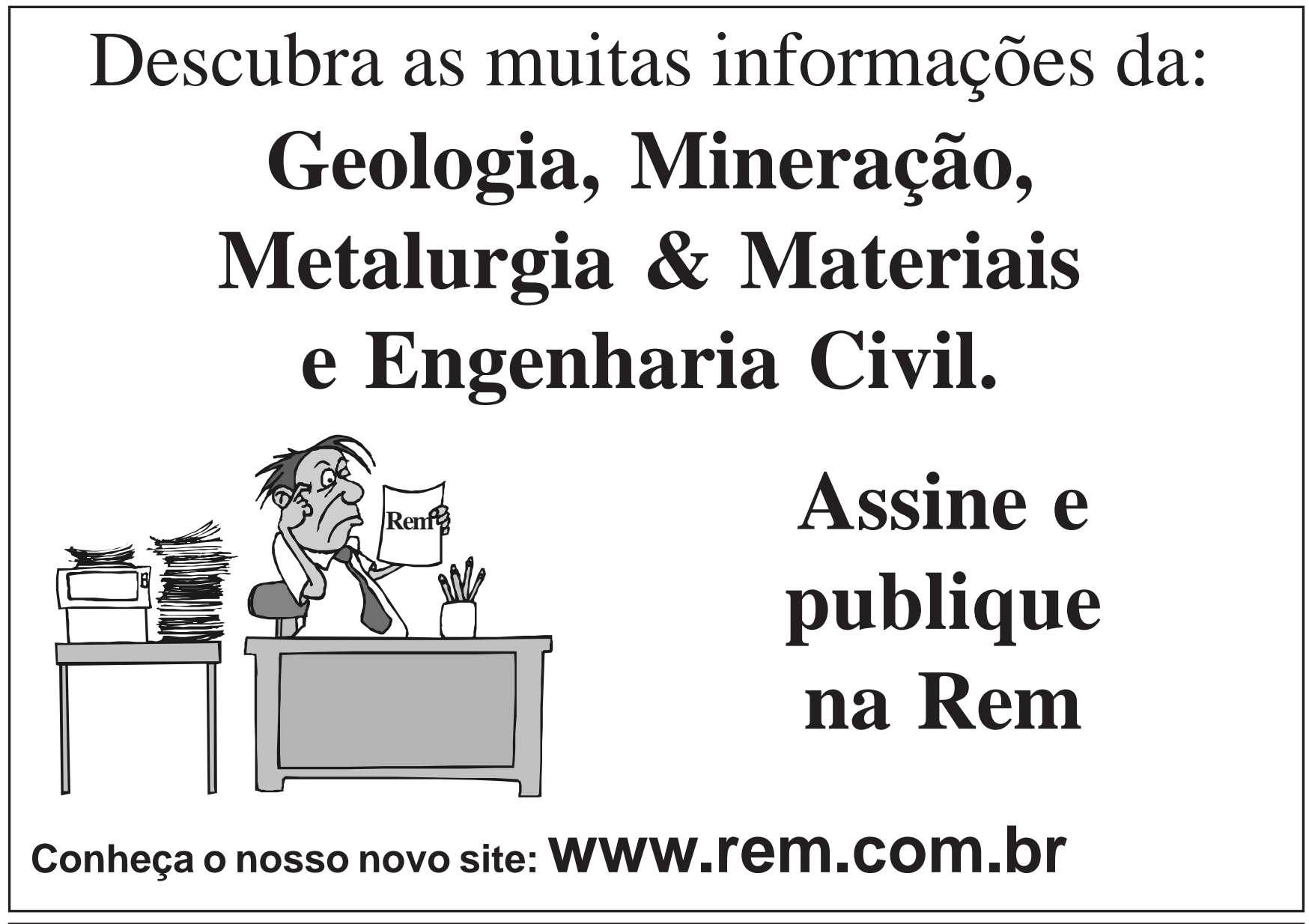

